\title{
¿El giro a la izquierda en América Latina?: un nuevo capítulo en la obra de Arditi
}

DOI: https://doi.org/10.32870/dse.v0i9.299

Arditi Benjamín (2014). La política en los bordes del liberalismo. Nueva edición 2014 Gedisa, Méixico.

\section{Mercedes Palencia Villa*}

Una de las cualidades de Benjamín Arditi es que escribe una obra generosa, que lleva al lector a exponer con claridad los conceptos complejos de la filosofía política y construye un texto, en el sentido etimológico de la palabra, pues teje de manera sostenida los hilos que sostienen su argumentación.

La introducción es un buen ejemplo de lo que encontrará el lector a lo largo del texto, ya que en el primer párrafo convierte en pregunta el título de su libro, y nos dice: ¿Qué significa hablar de la política en los bordes del liberalismo? Primero utiliza una metáfora orientacional, con el fin de explicar los bordes, el centro y diversos puntos en un espacio físico; esto permite al lector dibujar mentalmente sus acercamientos. Después nos advierte que las dicotomías nunca llegan a nada, y va más allá de las políticas híbridas. Recurre a Freud en lo relativo al síntoma como retorno de lo reprimido, para sostener que como los fenómenos sintomáticos no pueden estar adentro o afuera, sino en continuo juego, de ahí surge la periferia interna, en la cual la distinción de adentro y afuera es motivo de disputa y no puede ser especificada al margen de una polémica. Referirse a los fenómenos políticos en los bordes del liberalismo es pues, hablar de la periferia interna del liberalismo. El libro analiza estos bordes en distintos casos de las democracias actuales.

Hay tres secciones en la obra, por lo que explicaré brevemente las dos primeras y centraré la discusión en la última que conforma esta nueva edición. Espero no simplificar demasiado, la primera sección titulada "Identidad, diferencia y universales", abarca tres capítulos, en donde el lugar de la identidad es un sitio movedizo y las identidades están marcadas por las líneas de fuga del nómada. Antes que variables independientes, son construcciones siempre abiertas al cambio. A

\footnotetext{
* Departamento de Estudios en Educación barcelona.mercedes@gmail.com
} 
las identidades las denomina metaestables, pero nos advierte que no debemos considerarlas como construcciones circunstanciales, que cambian de un momento a otro; sino en un estado de equilibrio variable, una estabilidad oscilante.

Esto lo conduce en el segundo capítulo titulado el Reverso de la diferencia.

En el debate en torno a la diferencia y la identidad que cobra fuerza en la década de los ochenta, nos recuerda el papel que jugó la semiótica en las fases iniciales de la guerra en torno a las palabras. Por ejemplo las expresiones sexistas o discriminatorias. Esta desconfianza por los universales y énfasis en las diferencias, trajo consigo un rechazo a las grandes narrativas de la modernidad. En este contexto, surge la política de identidad, que fue convirtiéndose en una exaltación del nosotros, incompatible con formas más amplias.

Este es el momento en que el Reverso de la diferencia entra en escena: por un lado la misma oscilación que inaugura el nomadismo de las identidades, pero a la vez introduce incertidumbre en ellas. Esa incertidumbre puede ser un aspecto liberador, pero también acrecentar las demandas de seguridad identitaria, sea a través de la ortodoxia religiosa, el nacionalismo militante o la simbiosis entre colectivos humanos y líderes mesiánicos. Nos dice que surge un nuevo esencialismo: el de las diferencias. Centra su análisis en el debate de la posmodernidad a través de Gianni Vattimo, ya que le brinda un soporte conceptual para la política de las diferencias en la agenda pública.

En el tercer capítulo de esta primera parte, centra su atención en las impurezas de los derechos universales, y sostiene que es así que la defensa de la diferencia, cuestionó el universalismo y con ello el pensamiento liberal democrático, convirtiéndose en un desafío para los derechos ciudadanos.

Un ejemplo de ello, fueron la cuota como derecho especial, en nombre de un principio universal. Laclau propone una manera distinta que ha llamado una producción de universales y se basa en la lógica del significante. Por lo que afirma

que la universalidad aparece cuando una diferencia, sea un contenido particular o una demanda, se transforma en el significante de una plenitud ausente. La tarea de representar la ausencia, y, a su vez, la posibilidad misma de la universalidad (la igualdad), se establece a través de una medida específica (la cuota).También la cuota busca afirmar una diferencia de la identidad "nosotras las mujeres".

Sin embargo nos advierte, que esto no invalida la legitimidad de las cuotas como una medida de establecer la igualdad, sino más bien pone en cuestión los universales y con esto le permite demostrar que los derechos universales son constitutivamente impuros.

En esta misma discusión, retoma el mercado de divisas, y nos recuerda que durante la presidencia de Nixon en 1971, el mercado se quedó sin unidad de medida referencial, para determinar de manera fija la tasa de cambio. El conflicto sobre la paridad de monedas transcurre en un sistema, en donde se negocian intereses, dejando la deliberación a un lado. El ejemplo anterior, no conduce a que la negociación en la paridad de las monedas, pone límites a la pureza de las medidas de equi- 
valencia. Los anteriores argumentos tienen como finalidad llegar a la diferencia entre deliberación y confrontación, ejes que atraviesan las democracias actuales.

De ahí que la negociación es un límite de segundo grado, en donde se termina haciendo concesiones, pues sólo así existe negociación. Esto debilita los argumentos en favor de la idea de la igualdad irrestricta, y convierte la equivalencia en una categoría impura, distinta tanto de la identidad, pura como de la igualdad pura.

La segunda sección se denomina: "Populismo y democracia" consta de tres capítulos y centra la atención en los síntomas del populismo que lo empujan a los bordes de las democracias liberales. Con la finalidad de que el lector pueda comprenderlo, utiliza la imagen en donde el populismo se aleja de los modales en la mesa, a través del uso instrumental de movilizaciones populares y en la violencia callejera. De ahí que coloca al populismo en los bordes más ásperos del orden democrático liberal. Pero afirma, que es un retorno a lo reprimido, o un síntoma de la democracia, en la medida en que impide su cierre, en la presunta normalidad de procedimientos institucionales.

Hay un consenso de que el populismo no es un fenómeno independiente, debido a que se encuentra imbricado con la política contemporánea, como un fracaso de la democracia. El populismo funciona como espejo, en el que la democracia puede observar sus aristas, menos elegantes.

La tercera sección comprende tres capítulos: Emancipación, Revolución y Giro a la izquierda, éste último se anexó en esta edición.

El autor inicia asegurando que la agitación no es un remanente incómodo de la política caliente de antaño, sino que también sobrevive como periferia interna de la política institucional en democracias liberales. Sin embargo, hay un cierto descrédito de la agitación política, que ya no tiene un lugar dentro de las organizaciones, como lo fue anteriormente en los movimientos de izquierda, cuando se nombraba a un secretario de agitación y propaganda.

Para analizar la agitación, se remite a la frase de Bísmarck: "La política es el arte de lo posible", de la cual se apropian los realistas y consideran que la política debe basarse en hechos y no en ideologías. Sin embargo, en la realidad no pueden ser totalmente pragmáticos, en el momento de tomar decisiones y nos da varios ejemplos de ello. Lo que distingue a los realistas de un pensamiento utópico, es que para estos últimos, la emancipación conlleva una dimensión ética, la posibilidad de invocar imágenes de una sociedad buena. A pesar de ello, enfatiza que lo imposible o lo utópico impulsa a la gente a actuar como si fuera posible. De tal manera que lo posible no puede hacerse individualmente, sino en colectivo y la fuerza movilizadora de la emancipación deberá estar presente.

Para explicar este juego entre lo posible e imposible, retoma el concepto de subjetivación propuesto por Raciére, que pretende poner en entredicho la experiencia existente, a través de una estrategia retórica que busca alterar la supuesta naturalidad de un daño. Describe tres ejemplos, y yo sólo expondré uno que me pareció relevante "Una mujer negra era parte demandante en un caso judicial y el abogado le pregunta: ¿Cuál es su raza? Ella responde: la raza humana, y ¿cuál es su 
color de piel? Color natural, respondió". Su estrategia retórica busca alterar la supuesta naturalidad de un código racial jerárquico.

Este develamiento se convierte en operación política, en el sentido de Ranciere a través de la palabra; "la política pasa a ser concebida como manifestación de disenso, como presencia de dos mundos en uno". El autor señala que se traduce cierta interpretación del mundo a otro lenguaje de percepción, para así poder plantear la posibilidad de otro mundo menos opresivo y explotador. Hay un desplazamiento de la agitación hacia el develamiento y traducción.

También argumenta cómo lo revolucionario dejó de ser la toma del poder, como lo sostiene Holloway y un ejemplo que todos conocemos es el Ejército Zapatista de Liberación Nacional, que se ha negado a una lucha por tomar el gobierno, a pesar de su insistencia en construir un Estado distinto. De esta manera, la singularidad revolucionaria no consistirá de un epicentro o punto de quiebre que trabaja en solitario, sino de una multiplicidad de lugares discontinuos, desde donde se enuncian retos y desafíos del statu quo.

Sin embargo, los cambios no se plantean para un futuro lejano, y esplendoroso, sino que se estructuran en el ahora, como tiempo de nuestro devenir. Afirma el autor, que estas ideas, no son nuevas, ya que nos remiten a Gramsci, quien sostenía "una clase no toma el poder del Estado, sino que deviene Estado". Este devenir, son las zonas autónomas temporales que son parte de la revolución continua de la vida cotidiana.

El penúltimo capítulo titulado. "Después del duelo por la Revolución", advierte que el duelo no es para todos, sino para los revolucionarios que no lograron detener al capitalismo y triunfaron los defensores del libre mercado, hasta lograr un sistema económico que todos padecemos. En ese escenario, el autor hace un recorrido del significado revolucionario como derramamiento de sangre y violencia, pero nos recuerda que podemos explorar otras posibilidades de serlo. Para ello, busca desde Gramsci hasta Zizek, diferentes criterios para conservar el término revolucionario, como la capacidad de interrumpir y reconfigurar lugares de enunciación que no existían antes. Esto tendrá como resultado un desacuerdo, que desde el punto de vista de Raciere construye el objeto de argumentación y el campo mismo de la argumentación. Lo que lo conduce a preguntarse ¿Cuán radical debe ser una reestructuración del cosmos para poder ser considerada revolucionaria?

Propone como paso siguiente analizar la promesa y como se estructura, en el concepto de revolucionar. Para ello, analiza a Gramsci, Kant y Walter Benjamín para luego proponer un argumento acerca del revolucionar que retoma tres ideas de Derridá: la anticipación de algo por venir, el peso de lo imposible, y el estatuto del acontecimiento.

El anterior recorrido lo conduce a evidenciar que el término "revolución" aparece bajo distintas formas:

- Como entelequia de militantes e intelectuales.

- La revolución de los revolucionarios, como invocación mesiánica de un cambio radical con innumerables Mesías, dispuestos a indicarnos el camino. 
- La revolución como paradigma cultural de una generación y como punto de inflexión que, a la postre, puede terminar traicionando a quienes luchan por ella.

Debido a ello, la revolución es inseparable de una polémica o desacuerdo sobre su significado. Por lo cual está de acuerdo con Zizek cuando propone un leninismo renovado, el gesto y no la propuesta de Lenin, en el sentido imperativo de ser inventivo, para repensar un imaginario. Para lograrlo propone algunas postales:

\section{Primera postal: igualdad solidaridad en el nuevo internacionalismo}

Afirma cómo el fracaso de los llamados "socialismos reales" por un lado, y el auge del neoliberalismo, la igualdad y la solidaridad quedaron en un lugar secundario en la agenda política. A pesar de ello, nuevamente vuelve este imaginario igualitario en la escena pública doméstica e internacional pero de manera informal.

\section{Segunda Postal: el ruido de demos}

Coincide con Wolin en que la ciudadanía en términos de derechos statutarios, debilita la idea de ciudadanía, como poder o capacidad para crear nuevas políticas; el ciudadano no es un simple depositario de atributos, sino que la ciudadanía funciona como un operador que pone a prueba la veracidad de la libertad, la igualdad o la solidaridad.

Por lo tanto, la ciudadanía con el ruido de demos significa que no constituye una posición de sujeto, sino de agencia que está siendo producida en un proceso de subjetivación.

La subjetivación consiste según Raciére en lo que denomina ENTREMEDIO. Este implica dos procesos: una desclasificación, mediante la cual resiste el nombre, el lugar e identidad asignados, y la afirmación simultánea de una identidad que aún no existe. Pero la condición EN TRÁNSITO del entremedio también indica que uno, aún no adquiere nombre propio como grupo, porque el proceso de subjetivación ocurre en un cruce de nombres e identidades (Raciére 2000).

Para el autor esto coincide con la alusión de Blanchot en mayo del 1968, como un de estar-juntos, posibilidad que se refiere al surgimiento de un nosotros, que aún no se realiza, porque se trata de una comunidad por venir. De esta manera se desplaza la ciudadanía, a procesos de subjetivación que pone en escena diversos enunciados emancipatorios.

\section{Tercera postal: La política más allá de la representación Territorial}

Nos muestra que actualmente hay un segundo circuito de la política o ámbito de acción de actores extrapartidistas, o hacia fuera de las fronteras territoriales del Estado nación. Esto abre las puertas a una ciudadanía y un campo político supraestatal. Quienes participan en estos movimientos quieren intervenir en decisiones que se toman fuera de los Estados, de grandes jugadores globales, como 
conglomerados empresariales y hacerlos a ellos responsables de sus prácticas. Lo que implica replantear el campo de lo público y de lo político en espacios supranacionales.

\section{Cuarta postal: las políticas emancipadoras asincrónicas en el archipiélago}

Sostiene el autor que la idea de archipiélago posliberal desplaza, la representación territorial, como imagen rectora de la política. Sin embargo, esta expansión no es sólo numérica, dado que se modifican las coordenadas del campo político.

Este nuevo mapa viene sin un manual de cómo navegar, o cómo se deciden iniciativas políticas, pero tiene la ventaja de que -según el autor- refuerza la viabilidad de opciones políticas por fuera, de los parámetros habituales, como es el caso de las opciones que ofrece la red. Es así como la política emancipadora de carácter asincrónica y local, no implican proyectos de refundación total.

Estas postales, lo conducen al último capítulo, que se suma a esta nueva edición titulado: "El giro a la izquierda en América Latina: ¿una política posliberal?

Sostiene que hay razones prácticas para que los movimientos de izquierda se vayan adaptando a las condiciones actuales y sean permeables. Por lo tanto, resulta necesario un marco conceptual mínimo, para configurar las izquierdas en la época actual. Identifica tres factores interconectados:

1) Experiencia histórica.

2) Relación estratégica con el entorno cambiante.

3) La razón práctica, que se refiere a las representaciones de lo que es la izquierda, a través de panfletos.

Hace un recorrido histórico de las izquierdas y señala a la década de los sesenta como la época de gloria, generado por la revolución cubana y la experiencia guerrillera del Che Guevara. Asegura que parte de los setenta y ochenta fueron décadas perdidas para la izquierda. Afirma que aunque en Chile se dio la elección de Salvador Allende en 1970, y los golpes de Estado y la militarización de sus gobiernos, esto condujo a que el nuevo enemigo se configurara como los gobernantes autoritarios.

En mi opinión en México los setenta no fueron décadas perdidas ya que, al menos aquí se crearon diversos grupos radicales y los grupos menos radicales dieron asilo a intelectuales chilenos en universidades públicas, que tuvieron su impacto en la conformación de intelectuales de izquierda. Hay que recordar, por ejemplo, en 1978 el Festival mundial de la Juventud en Cuba, en donde se reunieron en la UNAM más de un centenar de jóvenes que irían a representar a la juventud de la izquierda de México. Salieron varios camiones desde la UNAM, hasta la Ciudad de Mérida, pero al llegar ahí, se les impidió salir como representantes de la juventud. La única delegación oficial de México, fueron las juventudes del PRI. 
Sin embargo, como bien señala el autor, la revolución conservadora desarrollada por Reagan y Margaret Thatcher en la década de los ochenta, rebasó a la izquierda por el lado económico, a través de la liberación y privatización. Esto afectó a todos los países de América Latina y llegó para quedarse el Neoliberalismo. Esto tuvo impacto en la izquierda parlamentaria, aceptando el consenso de Washington y la necesidad de ajustar las políticas sociales y convertir el Estado en administrador.

Por otra parte, el autor afirma que la única excepción significativa que difería con las otras izquierdas acerca de los mercados y las elecciones como una vía, residió en el surgimiento del EZLN en 1994, justo el mismo día que México firmó el Tratado de Libre Comercio de América del Norte.

Nos recuerda cómo las medidas económicas implementadas, han tenido repercusiones en el incremento de la desigualdad social y esto se ha manifestado a través de varios movimientos sociales. Por ejemplo, Chile a pesar de que era el arquetipo de éxito impulsado por el mercado, se ha convertido dentro de los países más desiguales.

La frase "Que se vayan todos" fue una consigna significativa no sólo para el movimiento de la clase media de las víctimas de "el corralito" Argentina, sino también de los movimientos de los cocaleros en Bolivia, estudiantes y mapuches en Chile, campesinos en Paraguay. Esta frase se convirtió en un entusiasmo para hacer otro tipo de política, y afirma que funcionaba como indicador de esta convergencia, como un síntoma de la dimensión posliberal, presente en el giro de la izquierda.

Por lo anterior, el autor señala que debido a los fracasos de los gobiernos para dar respuesta a las demandas, las izquierdas se vuelven más diversas, que las de décadas anteriores. Encuentra cierto consenso en que el pensamiento de izquierda hace referencia a buscar un cambio en el statu quo, porque vislumbra otro mundo más igualitario. Destaca ciertas coordenadas, pero se han alejado del libreto político marxista, aunque siguen concibiendo la igualdad, solidaridad y pensamiento crítico. Consideran que el Estado sigue siendo una instancia decisiva de regulación. Desconfían de la ambición de los Estados Unidos. Sin embargo, el proceso electoral se ha incorporado a ciertas izquierdas, como también en participaciones políticas posliberales.

Lo que me parece más interesante es su propuesta de indicadores que miden el éxito o fracaso de la izquierda. Él propone un desplazamiento de mapas cognitivos, que implican giros a la izquierda con o sin éxitos electorales. Es decir, si bien las victorias electorales funcionan como criterio predominante, habría que pensar fuera de los marcos establecidos. Porque cuando se gana el poder, se tienen que tomar decisiones impopulares que desilusionan a la ciudadanía. Su propuesta fuera de las contiendas electorales -no son nuevas-, ya que hace tiempo Gramsci afirmó que la fuerza política no toma el poder, sino que deviene Estado, a través de las guerras de posición. Zizek le llama "utopía escenificada" y Deleuze lo plantea como líneas de fuga o nomadismo. Un ejemplo de ello, son las resistencias en los regímenes autoritarios en el Cono Sur, en la décadas de los setenta y ochenta. Sobrevivían a pesar del hostigamiento de las autoridades, ubicándose a medio camino entre el statu quo y algo diferente por venir. 
Su propuesta va más allá de las elecciones, y sostiene que desde una agenda emergente se puede comenzar a gobernar, "que la capacidad constituyente propia de la dimensión performativa de la política, puede hacerse presente en todo el tiempo y en cualquier lugar".

Afirma que según el informe del Latinobarómetro del 2007, la desigualdad y la discriminación han pasado a formar parte de un tema central en la agenda pública, a tal grado que la derecha se ve ahora obligada a acercarse a la narrativa de la izquierda, como producción de un nuevo sentido político.

Este capítulo a diferencia de los demás, nos conduce a un optimismo necesario en el marco de la política performativa, porque permite poner en la mesa de discusión una dimensión posliberal que puede abanderar la política de la izquierda. Señala cómo en el campo académico, se han producido textos en donde la izquierda toma un papel predominante como fuerza de oposición, resistencia y cambio. Además afirma que las izquierdas latinoamericanas son hoy más posliberales, que antiliberales, en donde las elecciones no son el motivo de lucha, sino lugares y formatos fuera de esta democracia liberal.

Es así como menciona que, usando de manera libre las ideas de Foucault y Deleuze, el giro de la izquierda, "El liberalismo es lo que somos, pero también lo que gradualmente estamos dejando de ser, mientras el posliberalismo es un síntoma de lo que estamos en proceso de convertirnos, un indicador de nuestro devenir-otro". Sin embargo, no concibe el posliberalismo como una política que todavía no llega, sino que el porvenir lleva huellas de una utopía escenificada.

El autor nos presenta un posliberalismo abierto en donde caben diferentes posturas y para muestra basta un botón:

- Las propuestas de Schimitter, una de ellas consisten en empoderar a la ciudadanía a través de un pagaré y cuando no estén satisfechos con las opciones disponibles, dicho pagaré se destinará a un fondo común.

- Otros ejemplo de la política supranacional, por parte de actores no gubernamentales que no esperan a que los gobiernos les concedan derechos son:

1. Las redes de defensa internacional en América Latina;

2. Iniciativas de comercio justo, activismo cercano al Foro Social Mundial, y;

3. Protestas en contra de Organización mundial del comercio como las ocurridas en Seatle y Cancún.

Por lo anterior, nos acercamos a una política fuera del ámbito electoral más allá de los sitios y actores designados por la tradición liberal. América Latina está movilizada como nunca antes, y esto puede propiciar su propia liberación. Destaco un ejemplo que me pareció revelador: "Donoldo se refiere a la política homeopática, aquello en la que lo social es curado por lo social y la contrasta 
con la política alopática habitual, en la que las demandas hechas por la sociedad, son procesadas por una instancia fuera de ella".

La propuesta de Holloway sobre cambiar el mundo sin tomar el poder, reivindica vías no electorales para transformar lo dado, pero se pregunta ¿hasta qué punto es posible generalizar la experiencia zapatista y hasta donde es factible implementar políticas de redistribución si se rechaza a los partidos políticos y al Estado?

Se manifiestan también políticas híbridas, como en Argentina que coreaban "que se vayan todos" y sin embargo, la izquierda ganó las elecciones en el 2003. Sostiene el autor cómo podemos incidir en una redistribución de la riqueza sin el Estado y su importancia como regulador; como el impuesto Tobin, diseñado para castigar a la especulación financiera.

Esta nueva edición contribuye de manera importante a la reflexión política, desde diferentes enfoques teóricos, y este último capítulo, nos ayuda a comprender las causas de la diversidad de izquierdas en América Latina. 